\title{
Parental celiac disease and risk of asthma in offspring: a Danish nationwide cohort study
}

This article was published in the following Dove Press journal:

Clinical Epidemiology

29 December 2014

Number of times this article has been viewed

\author{
Ane Birgitte Telén \\ Andersen 1 \\ Rune Erichsen' \\ Michael David Kappelman² \\ Trine Frøslev' \\ Vera Ehrenstein' \\ 'Department of Clinical Epidemiology, \\ Aarhus University Hospital, \\ Aarhus, Denmark; ${ }^{2}$ Department \\ of Pediatrics, Division of Pediatric \\ Gastroenterology, University of North \\ Carolina at Chapel Hill, Chapel Hill, \\ NC, USA
}

Correspondence: Ane Birgitte Telén Andersen

Department of Clinical Epidemiology, Aarhus University Hospital, Olof Palmes Allé, 43-45, 8200 Aarhus N, Denmark Tel $+4587 \mid 68237$

Fax +4587167215

Email abta@clin.au.dk
Objective: The incidences of celiac disease (CD) and asthma are increasing and the two conditions are associated in individuals. Risk of asthma may be passed on to the next generation through shared risk factors. We examined whether parental CD is associated with risk of asthma in offspring.

Methods: We conducted a population-based Danish nationwide cohort study, using medical databases, covering the period 1 January 1979 to 31 December 2009. For each child with a parental history of CD, we randomly sampled 100 children without this history from the children born in the same calendar year. We used Cox proportional-hazards regression to estimate incidence rate ratios for asthma, adjusting for measured covariates.

Results: We identified 1,107 children with a parental history of CD and 110,700 children without this parental history. During up to 32 years of follow-up, 6,125 children received a hospital diagnosis of asthma. The adjusted incidence rate ratio for asthma associated with a parental history of CD was 1.09 (95\% confidence interval: $0.86-1.39)$ and was similar for maternal and paternal CD. Inclusion of asthma-medication in the definition of asthma did not substantially change the results.

Conclusion: There was no convincing evidence of an increased risk of asthma among offspring of parents with CD.

Keywords: asthma, celiac disease, children, cohort study, parents

\section{Introduction}

Celiac disease (CD) is a chronic immune-mediated disorder associated with villous atrophy and inflammation of the small intestine. ${ }^{1}$ It is caused by an immune reaction to gluten in genetically susceptible individuals. ${ }^{2}$ The prevalence and incidence of CD are increasing, particularly in Europe and North America, ${ }^{3,4}$ with an estimated current prevalence of $0.5 \%-1.5 \%{ }^{4,5}$ This trend probably results from a combination of better detection and true incidence increase, presumably in response to environmental exposures. ${ }^{4,6}$ The prevalence and incidence of asthma have been increasing concurrently with $\mathrm{CD}$. Asthma is the most common chronic childhood disease in Europe, affecting, on average, $10 \%$ of children. ${ }^{7,8}$

While asthma is a disease with a T-helper cell type 2 expression and CD has a T-helper cell type 1 expression, studies have shown that the two diseases are associated in individuals, ${ }^{9-12}$ suggesting shared genetic risk factors. The concurrent rapid increase in incidence suggests that the two diseases also share environmental risk factors. The shared risk factors remain largely unknown, although vitamin D deficiency may be implicated in the development of both $\mathrm{CD}$ and asthma. ${ }^{13,14}$ Another consideration is 
that patients with CD may suffer from vitamin D deficiency as a consequence of the disease. ${ }^{15}$ Vitamin $\mathrm{D}$ is a critical regulator of the immune system and may also improve fetal lung growth and maturation. ${ }^{16}$ Therefore, deficiency during pregnancy may increase risk of asthma in offspring. ${ }^{16-18}$ Currently, there is no epidemiologic evidence addressing the association between parental CD and asthma in offspring. We hypothesized that offspring of parents with CD have an increased risk of asthma. If an association is confirmed, it will help foster the understanding of shared risk factors. If an association exists only for maternal CD, it may point toward a pathway through maternal vitamin D deficiency. Such knowledge may contribute to early detection of children at risk of developing asthma, thus preventing under-diagnosis and under-treatment. ${ }^{7}$ We therefore conducted a populationbased nationwide cohort study using data linked from Danish medical registries.

\section{Materials and methods Setting and study population}

In this nationwide registry-based matched cohort study we included children born alive in Denmark from 1 January 1979 to 31 December 2009 whose parents had a medical history of CD. For each child with a parental history of CD we randomly selected 100 children without a parental history of CD, while matching on calendar year of birth. To ensure that all children had a minimum of 2 years' parental medical history, we only included children whose parents had lived in Denmark for a minimum of 2 years before the relevant child's birth. The children were identified from the Danish Medical Birth Registry (DMBR). Follow-up started on the date of birth and ended on the date of asthma onset, emigration, death, or 31 December 2010, whichever came first. The DMBR has recorded all births since 1973, including data on child, maternal, and paternal characteristics. ${ }^{19}$ We linked individual-level data on children and their parents to other Danish population health registries using the civil personal registration (CPR) number. The CPR number is a 10 digit unique identifier, assigned at birth or immigration since 1969 by the Civil Registration System and used in all public records. ${ }^{20}$ For children with missing father's CPR number in the DMBR, we identified fathers in the Civil Registration System.

\section{Data on parental CD}

Data on parental CD came from the Danish National Registry of Patients (DNRP). ${ }^{21}$ We searched the DNRP for CD diagnoses before the relevant conception for the fathers, and before the relevant delivery for the mothers. The DNRP has tracked all inpatient stays at non-psychiatric hospitals in Denmark since 1977. Reporting of emergency room and outpatient clinic contacts was added in 1995 . We used inpatient, outpatient or emergency room diagnoses of CD among the parents. The diagnoses were coded in the DNRP using the Eighth Revision of the International Classification of Diseases before 1994 and the Tenth Revision thereafter. To refine the CD definition, we also accessed data on biopsies recorded in the National Pathology Registry. The National Pathology Registry has a complete record of results of pathology procedures since 1997, classified according to the Danish version of the Systemized Nomenclature of Medicine. ${ }^{22}$ Thus, from 1997 onwards, confirmed CD biopsies were also used to define CD.

\section{Data on asthma}

We identified asthma in children based on inpatient, outpatient, and emergency-room discharge diagnoses recorded in the DNRP. We defined asthma onset as the date of the first asthma diagnosis. Using medical records as the gold standard, the positive predictive value and sensitivity of asthma diagnoses in children aged 6 to 14 years has been shown to be $85 \%$ and $90 \%$, respectively, in the DNRP. ${ }^{23}$

For the subgroup of children born in 1996 or later, the availability of prescription data from the Danish Registry of Medicinal Product Statistics (RMPS) ${ }^{24}$ allowed us to add an algorithm to the asthma definition based on a minimum of two dispensations of an inhaled $\beta$-agonist and a minimum of two dispensations of an inhaled corticosteroid, to ensure ongoing use. We have described and used this algorithm in previous studies. $^{25-27}$ In this subgroup of children, we thus defined asthma onset as the date of the first inpatient or outpatient asthma diagnosis or fulfilled prescription algorithm, whichever came first. The RMPS has recorded all prescriptions filled at Danish outpatient pharmacies since 1995, including the type of drug prescribed (according to the Anatomical Therapeutic Chemical classification system) and the date of dispensation. ${ }^{24}$ In a study from the US, a prescription for at least one inhaled $\beta$-agonist and one inhaled corticosteroid has a positive predictive value of $80 \%$ for identifying definitive asthma in individuals 5-45 years of age. ${ }^{28}$

\section{Data on covariates}

Based on the existing evidence we obtained information on a priori selected risk factors for asthma from Danish medical registries. ${ }^{29-35}$ From the DMBR, we procured data on sex of child, birth order, birth weight, gestational age, 
multiple gestation, mode of delivery, mother's age at birth, and maternal smoking during pregnancy (recorded from 1991). From the DNRP, we obtained hospital diagnoses of maternal and paternal asthma, and from the RMPS, data on maternal use of antibiotics during the relevant pregnancy. All algorithms used to define the study variables are provided in Table S1-S3.

\section{Statistical analyses}

Descriptive statistics were used to characterize the study population at birth according to parental CD status. We then estimated the 2 year and 10 year risk of asthma, treating death as a competing risk. ${ }^{36}$ We used stratified Cox proportionalhazards regression to compute crude and adjusted hazard ratios as estimates of incidence rate ratios (IRR and aIRR) with $95 \%$ confidence intervals (CI) for asthma, comparing children with a parental history of $\mathrm{CD}$ to children without this parental history. We examined the following categories of CD: parental CD, maternal CD only, and paternal CD only, adjusting for mode of delivery, birth order, multiple gestation, mother's age at delivery, and paternal and maternal asthma. The proportional-hazards assumption was assessed graphically and found to apply (Figures S1-S7).

Since some patients may have symptoms for several years before being diagnosed with $\mathrm{CD},{ }^{37}$ we repeated the analyses changing the parental medical history time window from a minimum of 2 years to a minimum of 10 years prior to their child's birth.

Because hospital-diagnosed asthma may represent the most severe disease, in another sensitivity analysis, we restricted the sample to children born in 1996 or later, in order to include the anti-asthma medication algorithm in the definition of asthma. This analysis included additional adjustment for maternal smoking and use of antibiotics during pregnancy. Finally, since asthma can be difficult to diagnose in small children, ${ }^{38}$ we conducted the analyses starting follow-up at age five years, both for the full cohort and for the restricted cohort of children born in 1996 or later, to allow inclusion of the anti-asthma medication algorithm and additional adjustment.

We used Stata software version 12 to analyze the data (StataCorp LP, College Station, TX, USA). The study was approved by the Danish Data Protection Agency (record no 2013-41-1790).

\section{Results}

We identified 1,107 children with parental history of CD and 110,700 children without such a parental history of
CD, matched by year of birth. Maternal CD accounted for $69 \%$ of all parental CD. First-born status, parental asthma, and maternal use of antibiotics were slightly more prevalent among children with parental CD than among those without (Table 1). All children contributed 806,332 person-years of follow-up and the median follow-up time was 7.4 years.

Table I Characteristics of children born in Denmark in 1979-2009 according to parental celiac disease $(n=\mid$ | I,807)

\begin{tabular}{|c|c|c|c|c|}
\hline \multirow[t]{2}{*}{ Characteristics } & \multicolumn{2}{|c|}{$\begin{array}{l}\text { Parental } \\
\text { celiac disease } \\
(n=I, 107)\end{array}$} & \multicolumn{2}{|c|}{$\begin{array}{l}\text { No parental } \\
\text { celiac disease } \\
(n=\mid 10,700)\end{array}$} \\
\hline & $\mathbf{n}$ & $\%$ & $\mathbf{n}$ & $\%$ \\
\hline \multicolumn{5}{|l|}{ Parental celiac disease } \\
\hline Maternal & 759 & 68.6 & & \\
\hline Paternal & 348 & 31.4 & & \\
\hline \multicolumn{5}{|l|}{ Sex of child } \\
\hline Male & 568 & 51.3 & 56,742 & 51.3 \\
\hline Female & 539 & 48.7 & 53,958 & 48.7 \\
\hline \multicolumn{5}{|l|}{ Birth order ${ }^{a}$} \\
\hline I & 536 & 48.4 & 48,149 & 43.5 \\
\hline$\geq 2$ & 571 & 51.6 & 62,551 & 56.5 \\
\hline \multicolumn{5}{|l|}{ Birth weight (grams) } \\
\hline$<2,500$ & 58 & 5.2 & 5,751 & 5.2 \\
\hline $2,500-3,499$ & 501 & 45.3 & 46,558 & 42.1 \\
\hline$\geq 3,500$ & 543 & 49.1 & 57,914 & 52.3 \\
\hline Missing & 5 & 0.5 & 477 & 0.4 \\
\hline \multicolumn{5}{|l|}{ Gestational age (weeks) } \\
\hline$<37$ & 68 & 6.1 & 7,133 & 6.4 \\
\hline $37-41$ & 967 & 87.4 & 95,432 & 86.2 \\
\hline$\geq 42$ & 66 & 6.0 & 7,543 & 6.8 \\
\hline Missing & 6 & 0.5 & 592 & 0.5 \\
\hline \multicolumn{5}{|l|}{ Mode of delivery } \\
\hline Vaginal & 864 & 78.1 & 89,067 & 80.5 \\
\hline Cesarean section & 243 & 21.9 & 21,633 & 19.5 \\
\hline \multicolumn{5}{|l|}{ Multiple gestation } \\
\hline Yes & 33 & 3.0 & 4,565 & 4.1 \\
\hline \multicolumn{5}{|c|}{ Mother's age at birth (years) } \\
\hline$<25$ & 156 & 14.1 & $|4,5| 8$ & 13.1 \\
\hline $25-34$ & 852 & 76.0 & 82,332 & 74.4 \\
\hline$\geq 35$ & 99 & 8.9 & 13,850 & 12.5 \\
\hline \multicolumn{5}{|l|}{ Maternal asthma } \\
\hline Yes & 39 & 3.5 & 2,648 & 2.4 \\
\hline \multicolumn{5}{|l|}{ Paternal asthma } \\
\hline \multirow[t]{2}{*}{ Yes } & 43 & 3.9 & 2,235 & 2.0 \\
\hline & $(n=9$ & & $(n=98$, & \\
\hline \multicolumn{5}{|c|}{ Maternal use of antibiotics during pregnancy ${ }^{b}$} \\
\hline Yes & 355 & 36.1 & 31,857 & 32.4 \\
\hline \multicolumn{5}{|c|}{ Maternal smoking during pregnancy ${ }^{b}$} \\
\hline No & 815 & 83.0 & 78,525 & 80.0 \\
\hline$\leq 10$ cigarettes/day & 107 & 10.9 & $|2,45|$ & 12.7 \\
\hline$>10$ cigarettes/day & 40 & 4.1 & 4,289 & 4.4 \\
\hline Missing & 20 & 2.0 & 2,935 & 3.0 \\
\hline
\end{tabular}

Notes: a Children of multiple births are coded in the same birth order; ${ }^{b}$ children born from 1996 onwards. 
During up to 32 years of observation, 68 children with parental CD and 6,057 children without this parental history had an asthma diagnosis. The median age at asthma onset was 1.5 years in both cohorts. When follow-up was started at the age of 5 years, the median age of asthma onset was 7.4 years. The 2 -year risk of asthma in the full cohort was $4.3 \%$ among children with a parental history of $\mathrm{CD}$ and $3.6 \%$ among children without this parental history; the 10 -year risks were $7.4 \%$ and $6.4 \%$, respectively (Figure 1).

Overall, the aIRR for asthma associated with parental CD was 1.09 (95\% CI: 0.86-1.39), with nearly no effect from adjustment for the covariates. Results did not vary according to maternal or paternal CD (Table 2).

In the sub-cohort of children born in 1996-2009, for whom we included anti-asthma medication in the asthma definition, we identified 982 children with a parental history of CD and 98,200 without this history. During up to 15 years of follow-up, 129 children with parental CD developed asthma compared to 11,120 children without parental CD. The aIRR for parental CD was 1.14 (95\% CI: 0.95-1.35), with similar estimates for maternal and paternal CD (other results not shown).

Changing the time window for a parental medical history of CD from a minimum of 2-10 years before their child's birth did not change the results. Finally, starting follow-up at age five in the full cohort and in children born in 1996 or later also did not substantially affect the results (data not shown).

\section{Discussion}

In this nationwide population-based cohort study with longterm complete follow-up and prospectively collected data, we found no convincing evidence for an association between

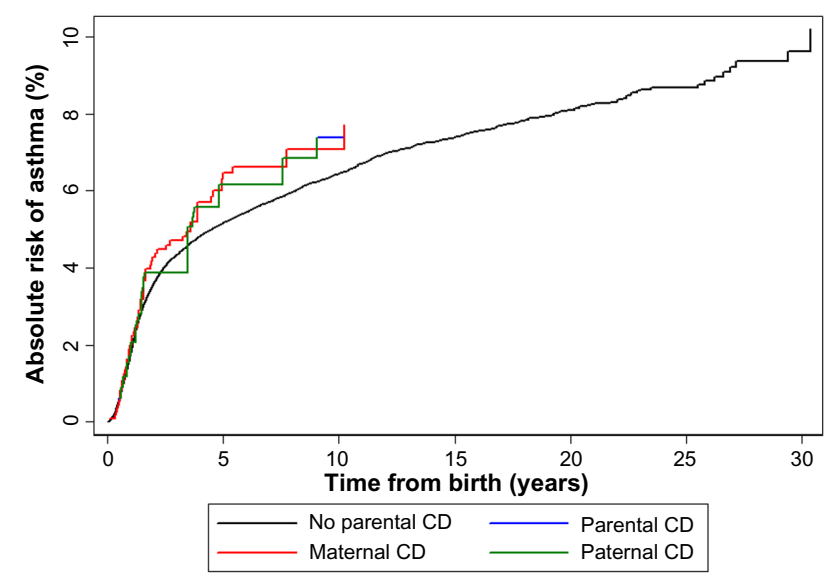

Figure I Absolute risk of asthma in children according to parental celiac disease (CD) status. parental CD and risk of asthma. The results were robust to different approaches to measuring the study variables and our study thus argues against a pathway of shared risk factors from parent to the next generation.

To the best of our knowledge, our study is the first to examine the association between parental $\mathrm{CD}$ and the risk of asthma in offspring. The association between $\mathrm{CD}$ and asthma within the same individuals has been examined in previous studies. Kero et al, in a cohort study of 59,867 children, including 114 children with $\mathrm{CD}$, reported an adjusted relative risk of asthma in children with $\mathrm{CD}$ of 7.26 (95\% CI: 4.49-11.01). ${ }^{12}$ Hemminki et al, using data from 3,006 patients hospitalized with asthma, reported a standardized incidence ratio for subsequent hospitalization with CD of 1.97 (95\% CI: 1.64-2.34). ${ }^{11}$ In a Swedish matched cohort study, including 28,281 individuals with CD and 140,295 individuals without $\mathrm{CD}$, the hazard ratio for asthma associated with CD was 1.61 (95\% CI: $1.50-1.72) .{ }^{10}$ Still, although examining a different association, our results are consistent with two previous studies examining family associations of CD and asthma. An Italian study compared the prevalence of allergies, including asthma, in individuals with CD $(n=1,044)$ with that of their CD-free first-degree relatives and spouses. ${ }^{39}$ The authors reported that no statistically significant difference in asthma prevalence was observed. Also, a small Italian case control study of 82 children with CD and 180 children without, reported no statistically significant difference in asthma prevalence among relatives of the two groups..$^{40}$ Neither of the studies reported relative estimates. The observed association of the two conditions in the same individual ${ }^{9-12}$ might be explained by host genetics and their interaction with environmental factors or vitamin D deficiency, with subsequent inability to control regulatory T-cell responses. ${ }^{10}$ Although our study argues against it, we cannot reject that $\mathrm{CD}$ and asthma share risk factors, however, a pathway from parent to child is not very likely.

The strengths of our study are its population-based cohort design with long-term and complete follow-up and use of prospectively collected data from population-based medical databases. The setting of a universal, tax-funded health care and routine registration of the events of interest virtually removes selection bias. We were also able to control for several important risk factors of asthma, including parental asthma and maternal smoking during pregnancy.

An important limitation of our study may be potential misclassification of the study variables. CD may have a silent clinical course for years with resolution of symptoms through 
Table 2 Crude and adjusted incidence rate ratios for asthma in Danish children born in 1979-2009, according to parental celiac disease status, $\mathrm{N}=\mathrm{I}$ I I,807

\begin{tabular}{|c|c|c|c|c|c|}
\hline & $\mathbf{N}$ & $\begin{array}{l}\text { Children } \\
\text { with asthma }\end{array}$ & $\begin{array}{l}\text { IR } \\
\text { (per I,000 PY) }\end{array}$ & $\begin{array}{l}\text { Crude IRR } \\
(95 \% \mathrm{Cl})\end{array}$ & $\begin{array}{l}\text { Adjusted IRR } \\
\text { (95\% Cl) }\end{array}$ \\
\hline \multicolumn{6}{|c|}{ Parental celiac disease } \\
\hline No & $\mathrm{I} 10,700$ & 6,057 & 7.6 & I.00 (Ref) & I.00 (Ref) \\
\hline Any parent & $\mathrm{I}, 107$ & 68 & 8.5 & $1.12(0.88-1.48)$ & $1.09(0.86-1.39)$ \\
\hline Maternal & 759 & 47 & 8.5 & I.II (0.83-I.48) & $1.09(0.8 \mathrm{I}-\mathrm{I} .45)$ \\
\hline Paternal & 348 & 21 & 8.5 & I.I3 (0.74-I.75) & I.II (0.72-I.70) \\
\hline
\end{tabular}

Note: aAdjustment: mode of delivery, multiple gestation, birth order, mother's age at delivery, asthma in mother, and asthma in father.

Abbreviations: $\mathrm{Cl}$, confidence interval; IR, incidence rate; IRR, incidence rate ratios; PY, person years.

a gluten-free diet, ${ }^{37}$ however, our results did not substantially change after extending the minimum parental medical history requirement from 2 years to 10 years. Any misclassification is likely to be non-differential with respect to development of asthma in offspring, and will bias the risk estimates toward the null. Misclassification of asthma among small children may also occur, and since we would expect it to be unrelated to parental CD, it may have produced bias toward the null if a true association existed. However, as our results were the same when we started follow-up at age five years, bias from misclassification of the asthma diagnosis does not appear to be of major importance.

We cannot completely rule out bias from unknown and unmeasured confounding, but to explain the lack of an observed association, a potential confounder would need to be protective of asthma. Breastfeeding may protect against development of both asthma and $\mathrm{CD},{ }^{41}$ and women with CD may have an increased awareness of the importance of breastfeeding. However, data on this variable are not recorded in Danish registries. Also, we lacked information on maternal use of vitamin supplements. It would be valuable to examine risk of asthma in children of mothers with treated CD during pregnancy (ie, CD diagnosed more than 1 year before pregnancy) versus mothers who were untreated during pregnancy. Finally, despite large sample size, precision of the estimates was suboptimal owing to small number of events among children with parental CD.

In conclusion, in this nationwide cohort study, we found no evidence of an association between parental CD and asthma in offspring.

\section{Acknowledgments}

The work was supported by the Department of Clinical Epidemiology Research Foundation, Aarhus University Hospital, Denmark. The Department of Clinical Epidemiology, Aarhus University Hospital, receives funding for other studies from companies in the form of research grants to (and administered by) Aarhus University. None of these studies have any relation to the present study.

\section{Disclosure}

The authors report no conflicts of interest in this work.

\section{References}

1. Ludvigsson JF, Green PH. Clinical management of coeliac disease. J Intern Med. 2011;269(6):560-71.

2. Pelkowski TD, Viera AJ. Celiac disease: diagnosis and management Am Fam Physician. 2014;89(2):99-105.

3. Ludvigsson JF, Rubio-Tapia A, van Dyke CT, et al. Increasing incidence of celiac disease in a North American population. Am J Gastroenterol. 2013;108(5):818-824.

4. Dydensborg S, Toftedal P, Biaggi M, Lillevang ST, Hansen DG, Husby S. Increasing prevalence of coeliac disease in Denmark: a linkage study combining national registries. Acta Paediatr. 2012;101(2):179-184.

5. Dube C, Rostom A, Sy R, et al. The prevalence of celiac disease in average-risk and at-risk Western European populations: a systematic review. Gastroenterology. 2005;128(4 Suppl 1):S57-S67.

6. Ma MX, John M, Forbes GM. Diagnostic dilemmas in celiac disease. Expert Rev Gastroenterol Hepatol. 2013;7(7):643-655.

7. Hafkamp-de Groen E, Mohangoo AD, de Jongste JC, et al. Early detection and counselling intervention of asthma symptoms in preschool children: study design of a cluster randomised controlled trial. $B M C$ Public Health. 2010;10:555.

8. Anandan C, Nurmatov U, van Schayck OC, Sheikh A. Is the prevalence of asthma declining? Systematic review of epidemiological studies. Allergy. 2010;65(2):152-167.

9. Ellul P, Vassallo M, Montefort S. Association of asthma and allergic rhinitis with celiac disease. Indian J Gastroenterol. 2005;24(6):270-271.

10. Ludvigsson JF, Hemminki K, Wahlstrom J, Almqvist C. Celiac disease confers a 1.6-fold increased risk of asthma: a nationwide population-based cohort study. J Allergy Clin Immunol. 2011;127(4): 1071-1073.

11. Hemminki K, Li X, Sundquist J, Sundquist K. Subsequent autoimmune or related disease in asthma patients: clustering of diseases or medical care? Ann Epidemiol. 2010;20(3):217-222.

12. Kero J, Gissler M, Hemminki E, Isolauri E. Could TH1 and TH2 diseases coexist? Evaluation of asthma incidence in children with coeliac disease, type 1 diabetes, or rheumatoid arthritis: a register study. J Allergy Clin Immunol. 2001;108(5):781-783.

13. Litonjua AA. Childhood asthma may be a consequence of vitamin D deficiency. Curr Opin Allergy Clin Immunol. 2009;9(3):202-207.

14. Tanpowpong P, Camargo CA. Early-life vitamin D deficiency and childhood-onset coeliac disease. Public Health Nutr. 2014;17(4):823-826.

15. Lucendo AJ, Garcia-Manzanares A. Bone mineral density in adult coeliac disease: An updated review. Rev Esp Enferm Dig. 2013;105(3): $154-162$. 
16. Litonjua AA, Weiss ST. Is vitamin D deficiency to blame for the asthma epidemic? J Allergy Clin Immunol. 2007;120(5):1031-1035.

17. Erkkola M, Nwaru BI, Viljakainen HT. Maternal vitamin D during pregnancy and its relation to immune-mediated diseases in the offspring. Vitam Horm. 2011;86:239-260.

18. Devereux G. Maternal diet during pregnancy: an emerging risk factor for childhood asthma. Expert Rev Clin Immunol. 2008;4(6):663-668.

19. Knudsen LB, Olsen J. The Danish Medical Birth Registry. Dan Med Bull. 1998;45(3):320-323.

20. Pedersen CB. The Danish Civil Registration System. Scand J Public Health. 2011;39(Suppl 7):22-25.

21. Lynge E, Sandegaard JL, Rebolj M. The Danish National Patient Register. Scand J Public Health. 2011;39(Suppl 7):30-33.

22. Erichsen R, Lash TL, Hamilton-Dutoit SJ, Bjerregaard B, Vyberg M, Pedersen L. Existing data sources for clinical epidemiology: the Danish National Pathology Registry and Data Bank. Clin Epidemiol. 2010;2: $51-56$.

23. Moth G, Vedsted P, Schiotz PO. National registry diagnoses agree with medical records on hospitalized asthmatic children. Acta Paediatr. 2007;96(10):1470-1473.

24. Kildemoes HW, Sorensen HT, Hallas J. The Danish National Prescription Registry. Scand J Public Health. 2011;39(Suppl 7):38-41.

25. Andersen AB, Ehrenstein V, Erichsen R, Froslev T, Sorensen HT. Parental inflammatory bowel disease and risk of asthma in offspring: a nationwide cohort study in Denmark. Clin Transl Gastroenterol. 2013;4:e41.

26. Andersen AB, Erichsen R, Farkas DK, Mehnert F, Ehrenstein V, Sorensen HT. Prenatal exposure to acid-suppressive drugs and the risk of childhood asthma: a population-based Danish cohort study. Aliment Pharmacol Ther. 2012;35(10):1190-1198.

27. Andersen A, Farkas D, Mehnert F, Ehrenstein V, Erichsen R. Use of prescription paracetamol during pregnancy and risk of asthma in children: a population-based Danish cohort study. Clin Epidemiol. 2012;(4):33-40.

28. Osborne ML, Vollmer WM, Johnson RE, Buist AS. Use of an automated prescription database to identify individuals with asthma. $J$ Clin Epidemiol. 1995;48(11):1393-1397.
29. Burke H, Leonardi-Bee J, Hashim A, et al. Prenatal and Passive Smoke Exposure and Incidence of Asthma and Wheeze: Systematic Review and Meta-analysis. Pediatrics. 2012;129(4):735-744.

30. Yuan W, Fonager K, Olsen J, Sorensen HT. Prenatal factors and use of anti-asthma medications in early childhood: a population-based Danish birth cohort study. Eur J Epidemiol. 2003;18(8):763-768.

31. Marra F, Marra CA, Richardson K, et al. Antibiotic use in children is associated with increased risk of asthma. Pediatrics. 2009;123(3): 1003-1010.

32. Davidson R, Roberts SE, Wotton CJ, Goldacre MJ. Influence of maternal and perinatal factors on subsequent hospitalisation for asthma in children: evidence from the Oxford record linkage study. BMC Pulm Med. 2010;10:14

33. Stensballe LG, Simonsen J, Jensen SM, Bonnelykke K, Bisgaard H. Use of antibiotics during pregnancy increases the risk of asthma in early childhood. J Pediatr. 2013;162(4):832-838. e3.

34. Thavagnanam S, Fleming J, Bromley A, Shields MD, Cardwell CR. A meta-analysis of the association between Caesarean section and childhood asthma. Clin Exp Allergy. 2008;38(4):629-633.

35. Lim RH, Kobzik L, Dahl M. Risk for asthma in offspring of asthmatic mothers versus fathers: a meta-analysis. PLoS One. 2010; 5(4):e10134.

36. Rothman KJ. Epidemiology: An introduction. New York: Oxford University Press, Inc.; 2002.

37. Green PH, Cellier C. Celiac disease. N Engl J Med. 2007;357(17): 1731-1743.

38. Bacharier LB, Boner A, Carlsen KH, et al. Diagnosis and treatment of asthma in childhood: a PRACTALL consensus report. Allergy. 2008;63(1):5-34.

39. Ciacci C, Cavallaro R, Iovino P, et al. Allergy prevalence in adult celiac disease. J Allergy Clin Immunol. 2004;113(6):1199-1203.

40. Greco L, De Seta L, D'Adamo G, et al. Atopy and coeliac disease: bias or true relation? Acta Paediatr Scand. 1990;79(6-7):670-674.

41. Ong KK, Forouhi N. Communicating the benefits of breast feeding. Arch Dis Child. 2007;92(6):471-472. 


\section{Supplementary materials}

Table SI ATC codes for included medications

\begin{tabular}{ll}
\hline Medication & ATC code \\
\hline Inhaled $\beta$-agonist & R03AC \\
Inhaled corticosteroid & R03BA \\
Systemic antibiotics & J0I \\
\hline
\end{tabular}

Abbreviation: ATC, Anatomical Therapeutic Chemical.

Table S2 ICD-8 and ICD- I 0 codes for celiac disease and asthma

\begin{tabular}{ll}
\hline Diagnosis & ICD codes \\
\hline Celiac disease & ICD-8: 269.00 \\
& ICD- I0: K90 \\
Asthma & ICD-8: 493 \\
& ICD- $0:$ J45, J46
\end{tabular}

Abbreviation: ICD, International Classification of Diseases.

Table S3 SNOMED-codes

\begin{tabular}{ll}
\hline Diagnosis & SNOMED code \\
\hline Celiac disease & T64020+M580I8 \\
& T65II0+M580I8 \\
& $T 64310+M 58018$ \\
& S62 I 80
\end{tabular}

Abbreviation: SNOMED, Systemized Nomenclature of Medicine.

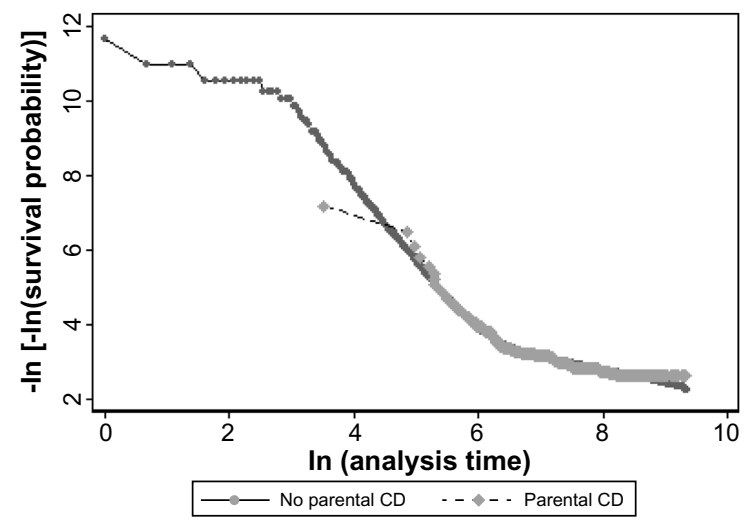

Figure SI Proportional-hazards assumption - parental celiac disease (CD).

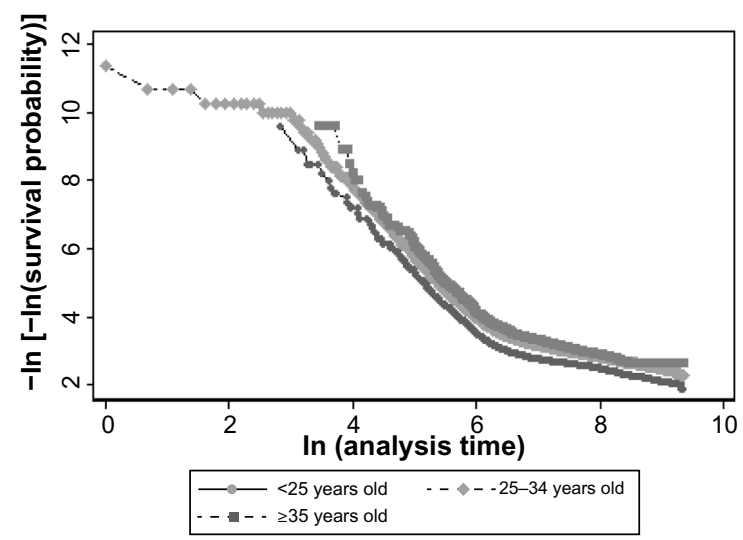

Figure S2 Proportional-hazards assumption - mother's age.

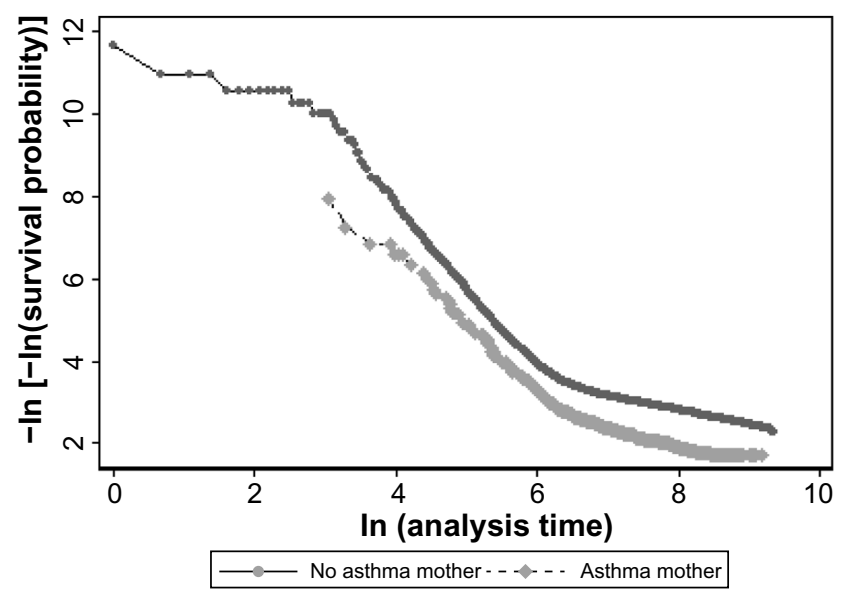

Figure S3 Proportional-hazards assumption - asthma, mother.

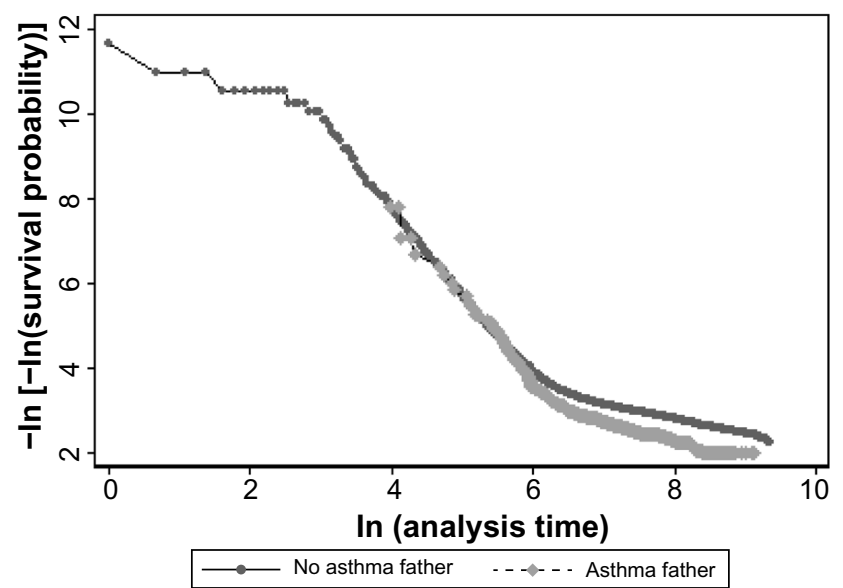

Figure S4 Proportional-hazards assumption - asthma, father.

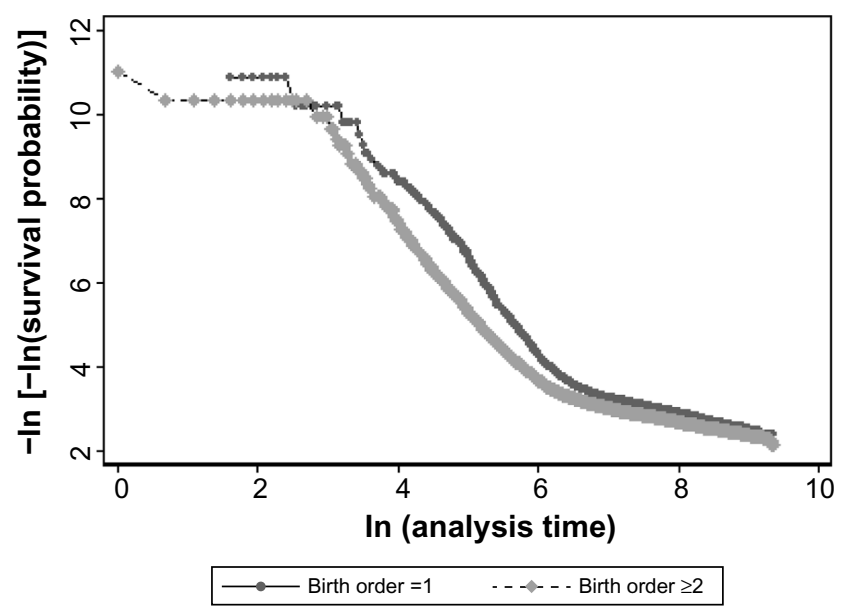

Figure S5 Proportional-hazards assumption - birth order. 


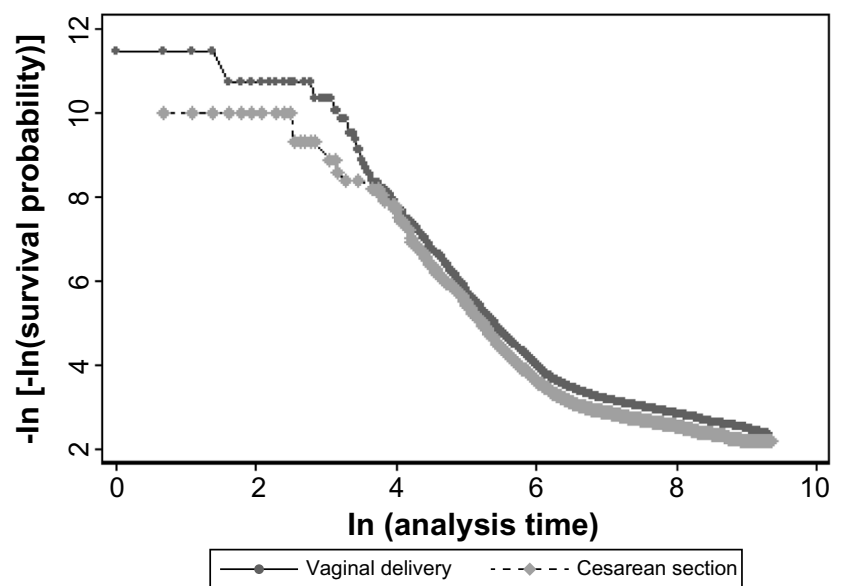

Figure S6 Proportional-hazards assumption - mode of delivery.

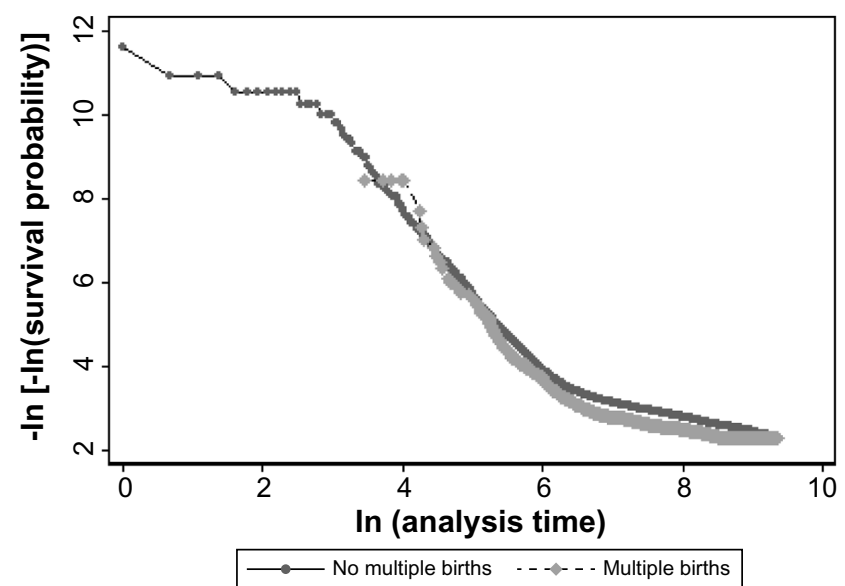

Figure S7 Proportional-hazards assumption - multiple births.

\section{Publish your work in this journal}

Clinical Epidemiology is an international, peer-reviewed, open access, online journal focusing on disease and drug epidemiology, identification of risk factors and screening procedures to develop optimal preventative initiatives and programs. Specific topics include: diagnosis, prognosis, treatment, screening, prevention, risk factor modification,

Submit your manuscript here: http://www.dovepress.com/clinical-epidemiology-journal systematic reviews, risk \& safety of medical interventions, epidemiology \& biostatistical methods, and evaluation of guidelines, translational medicine, health policies \& economic evaluations. The manuscript management system is completely online and includes a very quick and fair peer-review system, which is all easy to use. 